\title{
Clinical Study Functional Role
}

National Cancer Institute

\section{Source}

National Cancer Institute. Clinical Study Functional Role. NCI Thesaurus. Code C142438.

The responsibility assumed by a person administering any activities within a clinical study. 